\title{
Włodzimierz Zajączkowski - badacz folkloru ludów tureckich
}

\author{
Marzena Godzińska \\ Uniwersytet Warszawski \\ Wydział Orientalistyczny
}

\section{Włodzimierz Zajączkowski - a Researcher of Turkic Folklore}

Summary: Zajączkowski was a historian and turkologist who was interested not only in language and literature but also in traditional culture, which was not so popular among colleagues of his own generation. $\mathrm{He}$ conducted ethnographic research among Turkish peoples in a very professional manner. The most important of his works concern the Tatars of Dobruja and the Gagauz people. His main monographs are dedicated to these two groups, their language, literature, traditions and rituals. Today, Zajączkowski’s works are extremely valuable and unique.

Keywords: Włodzimierz Zajączkowski, Tatars of Dobruja, Gagauz, traditional culture, popular literature

Pośród turkologów pokolenia międzywojennego, a nawet powojennego rzadko można spotkać kogoś zainteresowanego folklorem i etnografią, czy też prowadzącego badania obejmujące zagadnienia z zakresu, jak dziś powiedzielibyśmy, antropologii kultury bądź etnologii. Osobą uzupełniająca tę lukę jest profesor Włodzimierz Zajączkowski. Przedmiotem jego zainteresowań była często kultura ludowa czy kultura tradycyjna wybranych ludów tureckich, zwyczaje i wierzenia ludowe. Nie pomijał przy tym, rzecz jasna, badań nad językiem, ale język i literatura były dlań źródłami, jakie mogły być wykorzystywane do dalszych badań nad kulturą, a nie celem samym w sobie. 
Urodził się w Wilnie 21 lipca 1914 r. Oboje rodzice, Józef i Nadzieja ze Szpakowskich, wyrośli w rodzinach, gdzie przywiązywano ogromną wagę do patriarchalnych tradycji domu i wzajemnego poszanowania członków rodziny. Wartości te rodzice profesora wpajali także swym dzieciom². W $1933 \mathrm{r}$. Zajączkowski ukończył gimnazjum imienia króla Zygmunta Augusta w Wilnie i rozpoczął studia w Krakowie, na Uniwersytecie Jagiellońskim, na Wydziale Filozoficznym. Pod opieką profesora Tadeusza Kowalskiego specjalizował się w zakresie Wschodu Muzułmańskiego i w 1937 r. uzyskał magisterium na podstawie pracy zatytułowanej: „Zapożyczenia arabskie i perskie w języku zachodniokaraimskim”. Ponieważ studiował równolegle historię, rok później uzyskał tytuł magistra historii. Podstawą była praca pod tytułem: „Chan tatarski Krym Girej i Polska”. Jeszcze jako student Uniwersytetu Jagiellońskiego, dzięki protekcji profesora Kowalskiego, Włodzimierz Zajączkowski został zatrudniony w charakterze asystenta w Katedrze Filologii Orientalnej. I natychmiast po zakończeniu studiów magisterskich rozpoczął zbieranie materiałów do rozprawy doktorskiej na temat Gaguzów, zamieszkującego na Bałkanach ludu tureckiego wyznającego prawosławie. W owym czasie był to lud de facto niezbadany, tak więc praca, jaką planował przedstawić Włodzimierz Zajączkowski, mogłaby mieć bardzo nowatorski charakter. Niestety, II wojna światowa zniweczyła jego plany naukowe.

Zaraz po wybuchu wojny wyjechał do Wilna, gdzie jako historyk znalazł posadę nauczyciela w jednej z polskojęzycznych szkół średnich. Po wojnie, dzięki staraniom Tadeusza Kowalskiego i Ananiasza Zajączkowskiego udało mu się powrócić do Krakowa². Tutaj, znowu dzięki pomocy profesora Tadeusza Kowalskiego, w owym czasie sekretarza generalnego Polskiej Akademii Umiejętności, został zatrudniony w tej instytucji na stanowisku urzędniczym. Do jego obowiązków należało prowadzenie rozmaitych prac pomocniczych związanych z podjętymi przez profesora Kowalskiego staraniami opracowania rękopiśmiennych tekstów karaimskich. Jednocześnie jednak Włodzimierz Zajączkowski powrócił do swoich przedwojennych gagauskich planów i w 1949 r. uzyskał tytuł doktora na podstawie rozprawy pod tytułem „Turcy-Gagauzowie - historia, język, etnografia”. W tym samym roku znalazł wreszcie zatrudnienie w Katedrze Filologii Orientalnej jako starszy asystent. W następnych latach

1 A. Dubiński, Włodzimierz Zajaczkowski in memoriam, „Przegląd Orientalistyczny” 1983, z. 1-4 (125-128), s. 183-187.

2 A. Sulimowicz, Polscy turkolodzy Karaimi. Od przedmiotu do podmiotu badań, [w:] Karaimi, red. B. Machul-Telus, Warszawa 2012, s. 136. 
uzyskiwał kolejne stopnie naukowe - docenta (1955), profesora nadzwyczajnego (1969) i profesora zwyczajnego (1980). Od 1973 r. kierował Zakładem Turkologii w Instytucie Filologii Orientalnej Uniwersytetu Jagiellońskiego. Zmarł w Krakowie, 3 września 1982 r., spoczywa w Warszawie, na cmentarzu karaimskim.

To, co zasługuje na szczególną uwagę w postaci i pracach Włodzimierza Zajączkowskiego, to metoda zbierania materiału. Podejmując badania nad kulturą ludów tureckich Zajączkowski nie ograniczał się do dostępnych tekstów literackich czy relacji podróżników, ale sam prowadził badania terenowe. Wyjeżdżał do Bułgarii, Rumunii, Jugosławii, Azerbejdżanu (radzieckiego). Owocem tych wypraw były liczne artykuły i kilka książek. Wiele artykułów poświęcił kulturze i językowi Karaimów. Interesującej monografii doczekali się Tatarzy z Dobrudży³. Ponadto w dorobku Włodzimierza Zajączkowskiego można znaleźć teksty na temat Tatarów krymskich czy tureckiej ludności Bałkanów4.

Szczególne miejsce w sercu i badaniach Zajączkowskiego od czasów doktoratu zajmowali jednak Gagauzowie. To im poświęcił najwięcej starań, dzięki czemu stał się nie tylko prekursorem badań nad kulturą tradycyjną Gagauzów, ale też i najwybitniejszym chyba w swej epoce znawcą tematu. Nie sposób nie wspomnieć tu o jego pracach na temat gagauskich tekstów folklorystycznych, terminologii zwierząt domowych u Gagauzów ${ }^{5}$ czy artykułu zatytułowanego Przyczynki do etnografii Gagauzów $w^{6}$, a zawierającego niezwykle interesujące informacje na temat obrzędowości i wierzeń gagauskich wraz z opisem wybranych zwyczajów i zachowań. Co więcej, profesor wskazał w tym tekście także szereg analogii pomiędzy kulturą Gagauzów i innych ludów tureckich, pośród których prowadził badania czy też kulturę których znał tylko z literatury przedmiotu. Opisy obyczajów, zachowań, nawet gestów wykonywanych przez rozmówców są tak obrazowe jasne i klarowne, że mogą służyć dziś jako wzór tego, jak należy sporządzać notatki terenowe, opisując, na przykład, składanie ofiary. Tekst jest przyczynkarski, taki też tytuł nosi artykuł, można by jednak życzyć sobie, aby każda przyczynkarska publikacja była równie wyczerpująca.

\footnotetext{
W. Zajączkowski, Język i folklor Tatarów z Dobrudży rumuńskiej, Wrocław 1975.

4 Pełna bibliografia prac W. Zajączkowskiego została opublikowana przez Aleksandra Dubińskiego: Prof.Dr. Wtodzimierz Zajaczkowski - On the Occasion of His 65th Birthday, „Ural-Altaische Jahrbücher” 1981, Neue Folge, t. 1, s. 255-269.

5 W. Zajączkowski, Gagauskie teksty folklorystyczne, Sofia 1960; tegoż, Terminologia zwierząt domowych u Gagauzów, „Rocznik Orientalistyczny”, t. 17, 1959, s. 386-392.

6 W. Zajączkowski, Przyczynki do etnografii Gagauzów, „Rocznik Orientalistyczny”, t. 20, 1956, s. 353-360.
} 
Zwieńczeniem i swoistym podsumowaniem prac gagauskich Zajączkowskiego jest monografia pod tytułem Jezyk i folklor Gagauzów $z$ Bułgarii, wydana w Krakowie w 1966 r., w nakładzie 600 egzemplarzy. W latach sześćdziesiątych czy siedemdziesiątych XX w. nakłady, także prac naukowych, sięgały niekiedy kilkudziesięciu tysięcy egzemplarzy. W tym konkretnym przypadku pamiętać należy jednak, że mamy do czynienia z publikacją specjalistyczną i bardzo hermetyczną. Nakład 600 egzemplarzy można więc uznać za imponujący. Praca ta w pierwszym rzędzie zawiera dość wyczerpujący opis języka Gagauzów, jego fonetyki, morfologii i składni. Drugą część książki stanowi wybór tekstów - znalazły się tu przysłowia, zagadki, przyśpiewki i piosenki ludowe, a także opisy obrzędów i ludowe opowiadania i bajki. Niestety, tekst jest de facto niedostępny dla szerszego grona czytelników, ponieważ wszelkie teksty gagauskie cytowane i przytaczane są w oryginale. Jednak zawarte w nich informacje stanowić mogą bardzo interesujący materiał dla zainteresowanego kulturą tradycyjną Gagauzów turkologa. Pewien niedosyt powoduje brak analizy i szerszego komentarza owych tekstów dokonany przez samego profesora Zajączkowskiego. Dziś komentowanie tekstów i wysnuwanie na ich podstawie wniosków przez młodsze pokolenie badaczy zawsze będzie mieć charakter analizy przeprowadzonej na podstawie cudzej relacji i cudzej dokumentacji. Z różnych innych wypowiedzi Włodzimierza Zajączkowskiego wynika jednoznacznie, że gdyby sam opisał badane ludy w sposób bardziej przystępny dla nie-turkologów, jego praca mogłaby się stać wręcz bestsellerem etnograficznym. Niestety, profesor Włodzimierz Zajączkowski nie stworzył takiej pracy, czego można tylko żałować. 